\title{
Al business model: an integrative business approach
}

\author{
Shrutika Mishra* and A. R. Tripathi
}

\author{
* Correspondence: shrutika.bhu@ \\ gmail.com \\ Faculty of Commerce, Banaras \\ Hindu University, Varanasi 221005, \\ India
}

\begin{abstract}
Artificial intelligence is the ecosphere's prevalent and most comprehensive general acquaintance common-sense cognitive engine. The artificial intelligence (Al) business platform model is virtually at affluence with cloud SaaS model. It concerns Al solutions that can work together on the top layer of the other digital systems, like a Customer Relationship Management (CRM) and Enterprise Resource Planning (ERP) business system. Al admittances in the digital data fluid through the coordination, fueling business enhancements over phases. In this business model, the business will safekeep a recurrent subscription. This paper endeavors to emphasize on the preventative side of the use of $\mathrm{Al}$ and machine learning $(\mathrm{ML})$ technology to enterprise digital platform business model innovation and business dynamics. We acme the strategic implications and innovations with analytics. We explore the derivations of data-driven insights, models, and visualizations.
\end{abstract}

Keywords: Business model innovation, Artificial intelligence, Emerging technology, Business platform, Digital innovation

\section{Introduction}

Artificial intelligence and machine learning models are computational and mathematical algorithmic models which execute trained data and humanoid experiences input to produce a decision an expert would make when provided that same information (Alhashmi, Salloum, \& Abdallah, 2019, Gentsch, 2018a, González-González \& Jiménez-Zarco, 2014, Yorks, Rotatori, Sung, \& Justice, 2020). In other sense, artificial intelligence (AI) is the capability of a processor to accomplish jobs that are analogous (at least in a limited sense) to that of human wisdom and decision production (Alhashmi et al., 2019; Antón, McCracken, \& Potts, 1994; Dimitras, Slowinski, Susmaga, \& Zopounidis, 1999; Eiteman, Stonehill, \& Moffett, 1989; Yoffie, Kind, \& Shimol, 2016). In the 1950s, John McCarthy thinks up the term "artificial intelligence," and Marvin Minsky was a well-known scientist in the field (Antón et al., 1994; Burgess, 2018). A model attempts to do from scratch a specific decision method that a group of specialists would make if they could analyze all existing data (Burgess, 2017; Eiteman et al., 1989; Fountaine, McCarthy, \& Saleh, 2019).

(c) The Author(s). 2021 Open Access This article is licensed under a Creative Commons Attribution 4.0 International License, which permits use, sharing, adaptation, distribution and reproduction in any medium or format, as long as you give appropriate credit to the original author(s) and the source, provide a link to the Creative Commons licence, and indicate if changes were made. The images or other third party material in this article are included in the article's Creative Commons licence, unless indicated otherwise in a credit line to the material. If material is not included in the article's Creative Commons licence and your intended use is not permitted by statutory regulation or exceeds the permitted use, you will need to obtain permission directly from the copyright holder. To view a copy of this licence, visit http://creativecommons.org/licenses/by/4.0/. 
Artificial intelligence (AI) has been changing businesses as proven by Airbnb, Ola, Uber, Flip cart, e-Bay, Amazon, Mantra, etc. and other enterprises that have incorporated its use to instrument state-of-the-art business models (Fountaine et al., 2019, Mishra \& Triptahi, 2019, 2020a, 2020b). This embryonic and quickly advancing technology impacts digital platform business model innovation (Arnold \& Scheutz, 2018), although many businesses are being made exposed to new entrants armed with the technology. Unfolding AI technology as the promoter of digital business model innovation, this study outhouses gracefully depending on issues influencing digital business model innovation start up through evolving technology (González-González \& Jiménez-Zarco, 2014, Mishra \& Triptahi, 2019, 2020a). The goal line of artificial intelligence in business is to look out advance cutting-edge research in the fields of AI and machine learning, as well as interrelated arenas like cryptography, cryptocurrency, and innovation to develop a way out that is utmost impactful to the business's customers and industries (Corea, 2019; Mishra, 2018). In this way, continuous intelligence (CI) is a design pattern in which on line real-time data analytics are cohesive into business processes, meeting out contemporary and chronological data to advise movements in comeback to business ticks and other significant measures (Charif \& Awad, 2014). Applied intelligence (AI) is a smarter, faster, and more effective approach to collecting, processing, and analyzing data, creating insights which help identify clear opportunity to act on and automating those actions where possible to unlock business significance (Corea, 2019, Mishra \& Tripathi, 2020c, Yorks et al., 2020). It is advantageous for businesses to gaze at $\mathrm{AI}$ from side to side on the lens of business proficiencies rather than expertise with technology. AI can upkeep three significant business essentials (Fountaine et al., 2019, Yorks et al., 2020): computerizing automated business process from back office executive and business activities; acquisition of intuitions through data scrutiny, breakdown, data analysis, and performance metrics; and engaging with consumers and workforces (Burgess, 2017; Corea, 2019). Data and knowledge, learning from experiences, reasoning and planning, safe human interaction through AI technology, multiagent systems, secure and private artificial intelligence communication, and machine vision and language processing are some of the key hubs of artificial intelligence (Burgess, 2018, Fountaine et al., 2019, Schulte \& Liu, 2017). These things with their significant landscapes can be pictorially represented as below (Fig. 1).

The rest of the paper is organized as follows. "Methods and experimental design" section summarizes the methods and experimental design on AI business model ecosystem. In "Future trends of platform business model optimization" section, we discuss about the future trends of platform business model optimization. "Business model data challenges" section studies the business model challenges. "Business model transformation" section explores the business model transformation while "Security and privacy terrorizations" section discuss about the security and privacy terrorizations. "Results and discussion" section deduces the case study and discussion, and finally, "Conclusions" section concludes the paper.

\section{Methods and experimental design}

The business intelligence and artificial intelligence are some of the cutting-edge methods and tools to renovate the business for automated systems. These state-of-theart tools are useful for design, invention and advertising, soft promotion, marketing, 


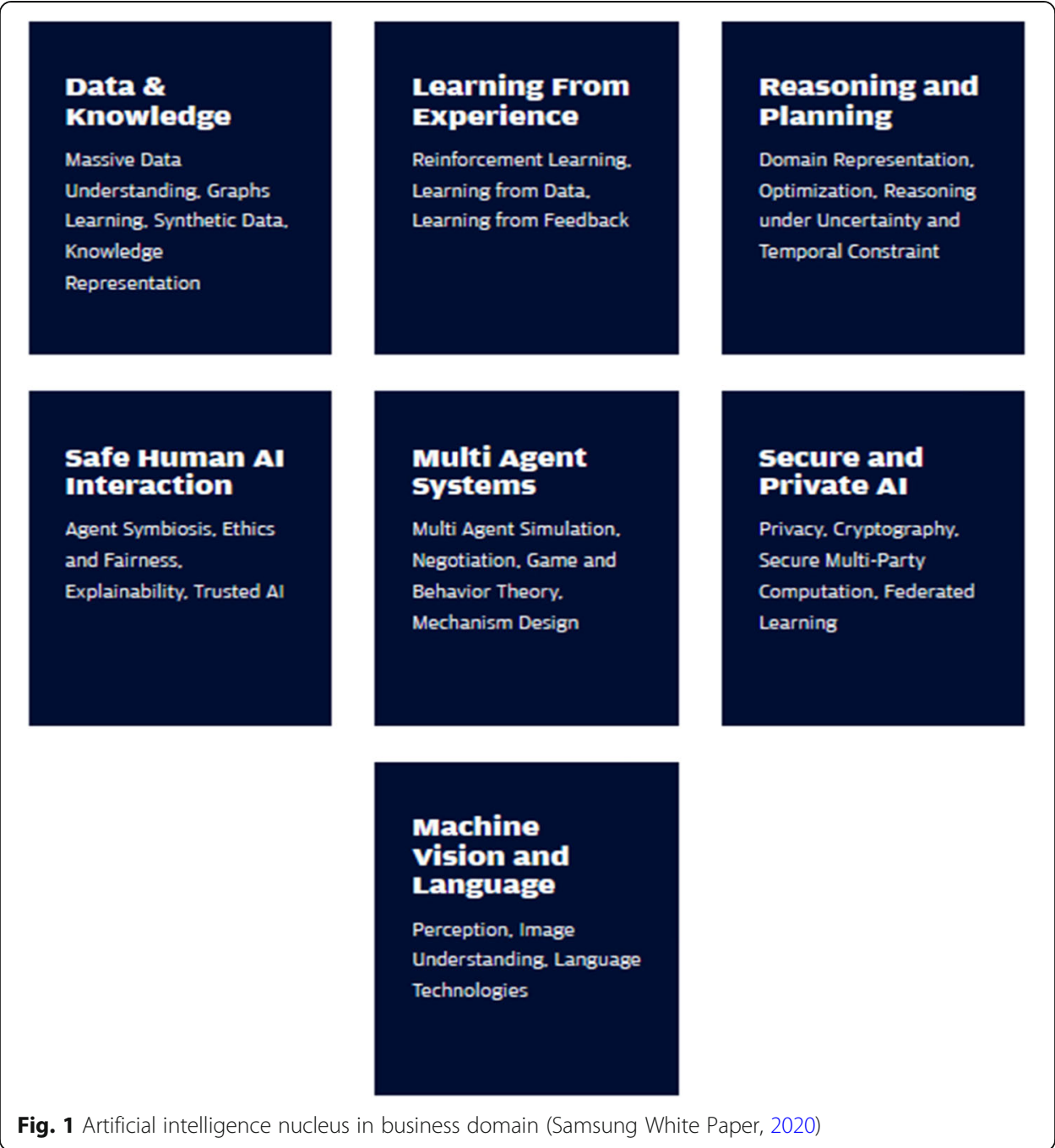

and selling age which are almost synchronizing with the platform business model. The artificial intelligence and data intelligence tools are growing over the period (Armour \& Sako, 2020, Mishra, 2018, Mishra \& Tripathi, 2020, 2019). The exponential growth of artificial intelligence and cloud computing step up the connotation of thoughts, design, innovation, opinions, cognitions, beliefs, feelings, and appreciation (Fountaine et al., 2019). Therefore, the opportunity of growth of AI business models becomes more and more over the years with data and business intelligence (Armour \& Sako, 2020).

Now a day's companies are using data intelligence to flourish their business along with artificial intelligence. Data intelligence (DI) is a dynamic part of any establishment's energies to recover the amenities and revolutionary state-of-the-art policies they pay (Charif \& Awad, 2014). One of the most conjoint uses of data intelligence is to cognize customer inclinations (Muthuveloo \& Ping, 2013). By using data mining techniques to collect statistics regarding habits, shopping preferences, buying behaviors, price tagging preferences, color choices, style preferences online trends, and other individual information, enterprises can mold their services better and comprehend affinities 


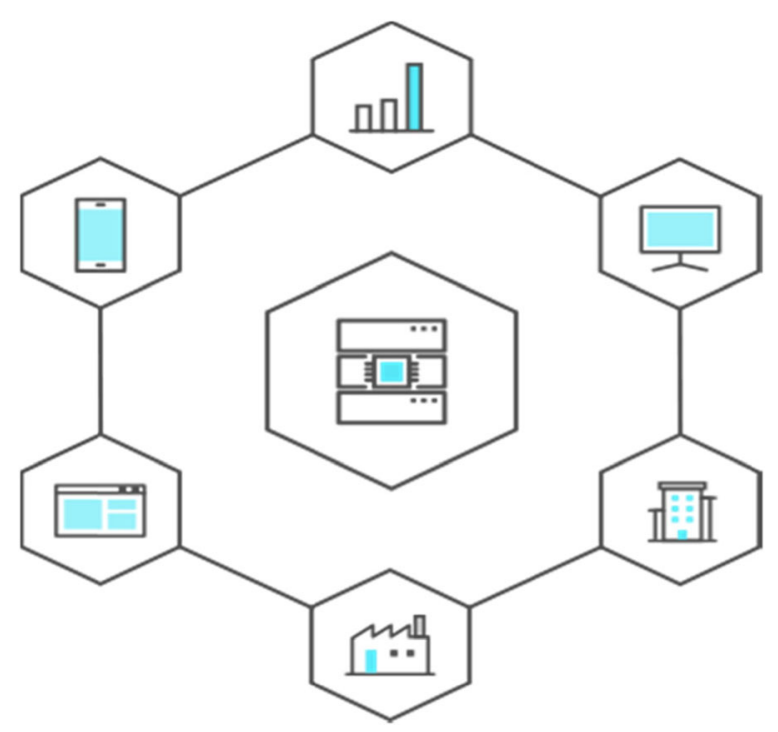

Fig. 2 Design of data intelligence in business ecosystem

across their bull's eye demographics. The structure of data intelligence is depicted as below (Fig. 2).

Artificial intelligence (AI) is now competent enough to rebuild the business strategy and trade across the globe. Industrialization and emergent growth of technology innovation, synchronization of different communication channels through 4G LTE, 5G technology immense the business culture. From the last few decades, artificial intelligence (AI) and machine learning (ML) algorithms become ubiquitous in business arena and solve many cutting-edge business applications and create knowledge-based portfolio for upcoming businesses (Ferrario, Loi, \& Viganò, 2019, Samsung White Paper, 2020). On the consequences, AI has helped many businesses to improve the manufacturing cost, productivity, technological synchronization, and automatic update and solve the global economy on the business earth (Armour \& Sako, 2020, Furman \& Seamans, 2019). Nowadays, business management and its executive part are undergoing basic changes and applying business process engineering all over the globe (Burgess, 2018). One of the key challenges almost all executives face today is that of allocating with and treatment digital transformation in their originations (Fountaine et al., 2019). This is a force that is modeling business and the intact competitive business landscape. Executives are fronting this challenge with capricious degrees of gusto. The business technological metrics help to express specific and mutual attainment in emerging AI competencies for industries. Admitting this evolving genuineness, risk group introduced a much-needed conversation on artificial intelligence for business on risk roundup (Ciuriak, 2019; Ferrario et al., 2019).

Research Question - How artificial intelligence and its associate machine learning and hologram technology renovating business ecosystem and how it revolutionizes business platform and commerce ecosystem in coming generation?

In this paper, we are trying to explore the solutions of these questions which is the need of the times. 


\section{Future trends of platform business model optimization}

The software technology is developing very fast which naturally impacts the business culture, business modeling, platform scaling, selling and buying behavior, pattern, and even the communication trend for business (Dimitras, Zanakis, \& Zopounidis, 1996, Huang \& Hu, 2003, Xu et al., 2018). With the swift enlargement of a new age bracket of information and communication technology such as cloud computing, Internet of Things, big data, mobile internet, artificial intelligence, etc. and its uninterrupted indepth applications in the business and industry developing period of intelligent manufacturing are coming (Schulte \& Liu, 2017; Xu, Turunen, Ahokangas, Mäntymäki, \& Heikkilä, 2018). Simulation optimization and scheduling in intelligent and smart businesses have productive realizations in principle as well as in practice (Valanarasu, 2019). Artificial intelligence has a great role in business modeling and platform business (Aldinucci et al., 2018; Åström, 2020; Morley, Floridi, Kinsey, \& Elhalal, 2019). However, there are still some potential research projections in this arena commendable to be deliberate yet to come. Below are some future projections of AI platform business model.

\section{Innovations in Al business model}

Artificial intelligence is drifting out of R\&D labs and into the business world. Millions of industries across the globe and top-notch companies are fitting together the power of AI and Applied artificial intelligence (AAI). Most of the business industries spot the scams using machine learning algorithms in nanoseconds to improve customer satisfactions. A vivid rise in the machine learning tools, business platforms, and applicationsbased tools were developed to quench the business satisfactions (Alhashmi et al., 2019, Dimitras et al., 1999, Mishra \& Tripathi, 2020b).

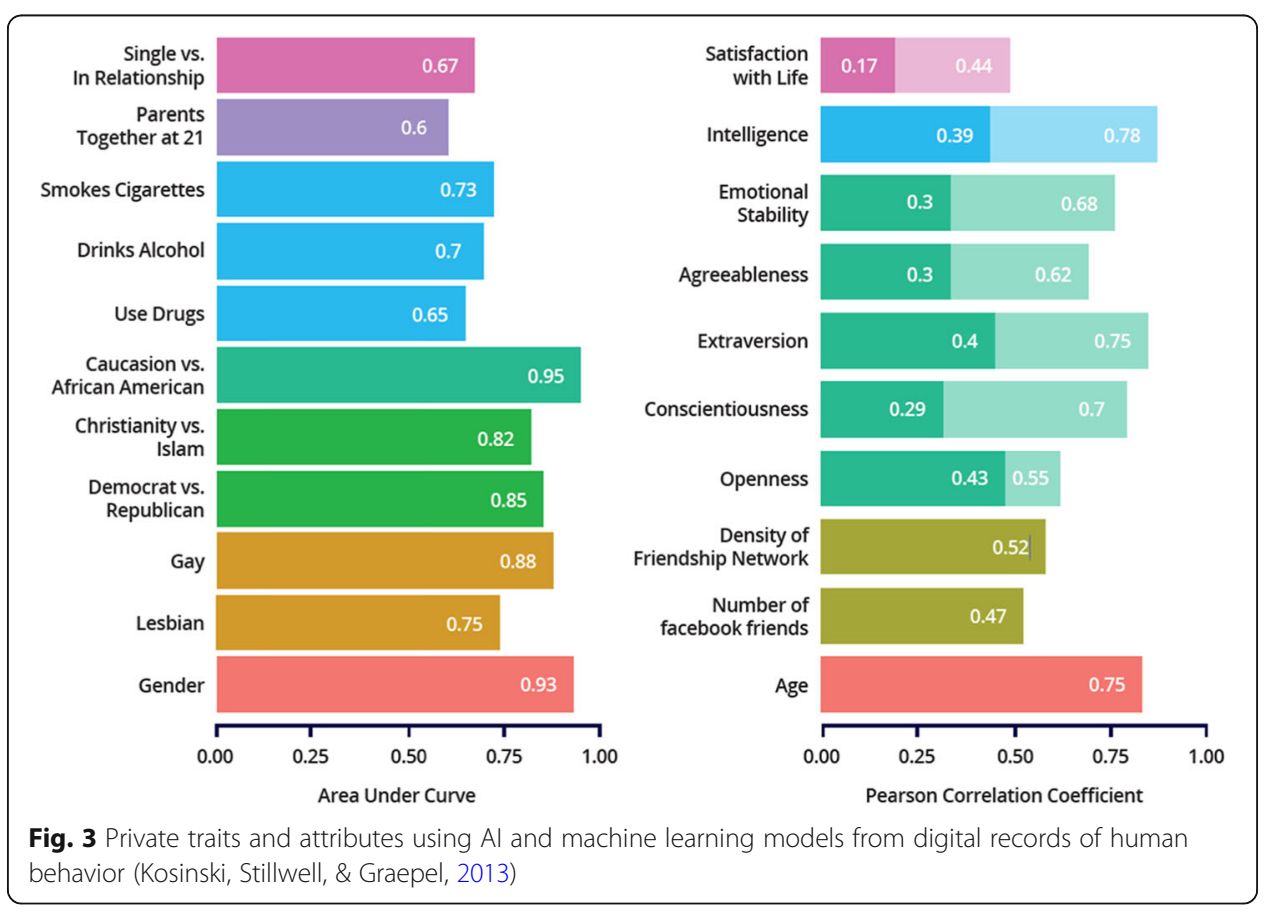


These state-of-the-art technologies not only compressed the quality of the internet and the software industry but also other verticals such as built-up, healthcare system, legal, automobile, and agriculture as well (Casadesus-Masanell \& Ricart, 2011).

Most of the top-notch companies like Microsoft, Facebook, Apple, Google, Amazon, Myntra, Flipkart, and IBM are financing R\&D of applied intelligence and artificial intelligence, for the benefits of the company and customers. Some private traits and attributes are predictable using AI and machine learning algorithms from digital records of human behavior as shown below (Morley et al., 2019) (Fig. 3).

\section{Growth of Al-enabled ultra-smart mini and micro chips}

The future of AI-enabled chips is booming in the business industry and AI and machine learning-based model is playing countless and multidimensional segment for the evolution. The necessity of artificial intelligence on focused processors is the motive for the augmentation in AI-enabled chips. Even with the fastest central processing units, GPUs might not recover the speed of working out an AI model. To speed up the execution of AI-enabled apps, the chip manufacturers such as Intel, AMD, NVIDIA, and Qualcomm will be shipping dedicated AI chips. These chips will be optimized for scenarios like NLP in computing, vision, and speech recognition. For delivering intelligence, applications from the high-tech automobile and high-tech healthcare industries will rely on these ultra-smart chips (Casadesus-Masanell \& Ricart, 2011).

\section{The eminence of autoencoder and automated machine learning}

An evolutionary movement that is going to transform ML-based solutions is automated ML. The foremost way of automation in machine learning (ML) will be the authorization of inventors and developers for business analysts and data analytics to go forward. Machine learning models could address the multifaceted state of affairs without going through the emblematic development of training the machine learning models (Casadesus-Masanell \& Ricart, 2011).

\section{Smart automation by Al}

A colossal quantity of log data which is produced by up-to-the-minute setup and applications is netted for sorting, searching, indexing, and data analytics. These gigantic data sets can be amassed and interconnected to find patterns and insights (Massa, Tucci, \& Afuah, 2017).

\section{The convergence of Al with other emerging technologies}

The convergence of IoT with AI and AI with blockchain is a new paradigm of business model (Casadesus-Masanell \& Ricart, 2011). In fact, self-driving cars cannot be a practical possibility without IoT working closely with AI. In the near future, we will be appreciating the driverless car with the use of AI and IoT. This model certainly will be the succeeding step of the rebellion in business, decision theory, and optimization theory, along with the software industry. The software used in decision-making is powered by AI models, and the sensors used by cars to collect real-time data are enabled by the IoT sensors (Mishra \& Tripathi, 2020a). The deep learning business model and AI- 


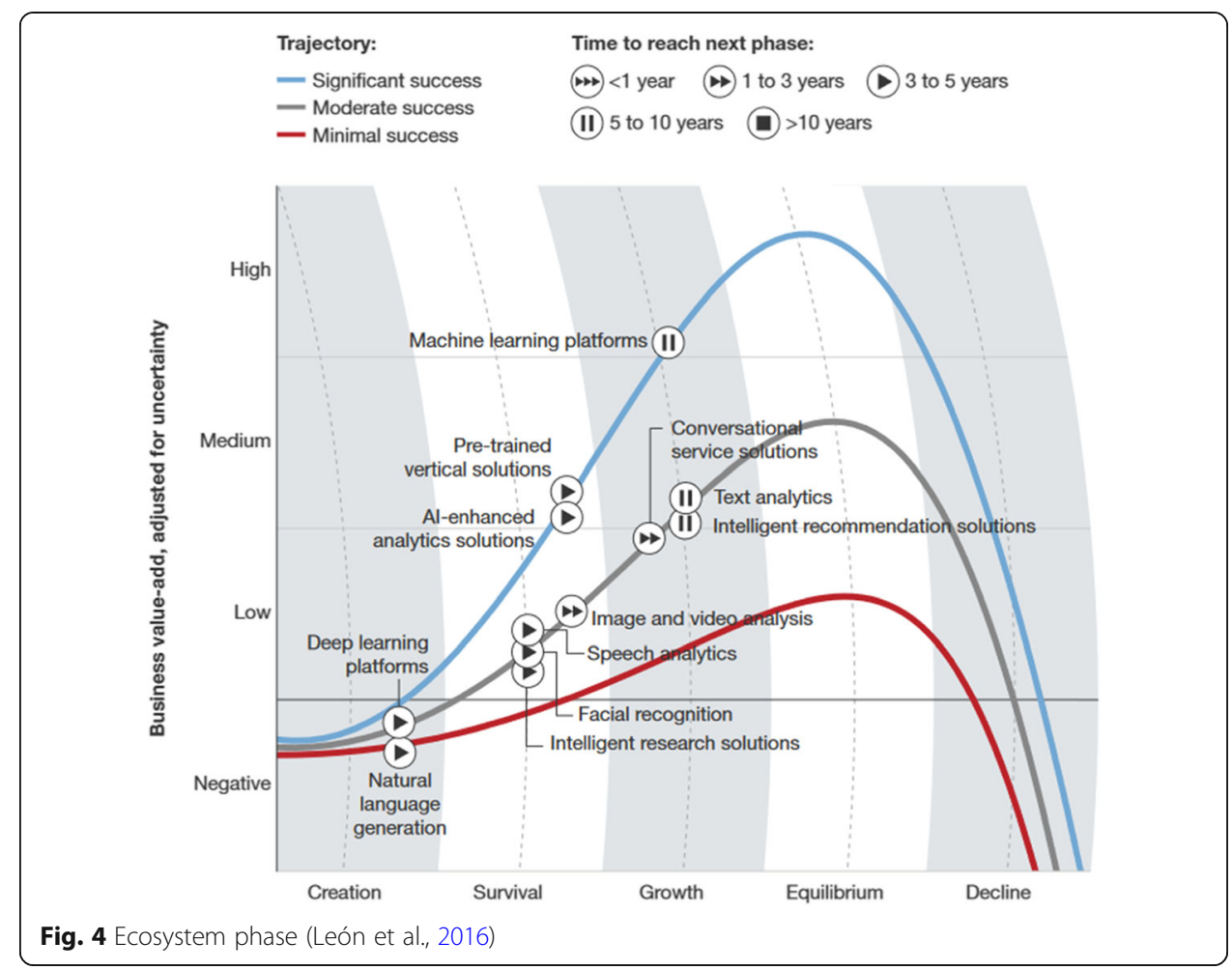

based algorithms take decisive action and also make fruitful decisions using these data. The ecosystem phase is elaborated as below (León et al., 2016) (Fig. 4).

\section{Deep learning models will be the hottest Al skill}

AI jobs with knowledge of deep learning are growing at a quicker hop. Deep learning is a type of machine learning which develops algorithms known as artificial neural networks that work by modeling the structure and functions of the human brain and cognition (León et al., 2016, Mishra \& Triptahi, 2019).

\section{Enhancing efficiency and efficacy}

Using AI technology with deep learning model, we will be able to do a huge number of tasks, but getting more throughput. The universal AI example is more visible in the form of voice recognition, Google Assistance, Alexa, and Siri; there is gigantic rendezvous (Mishra \& Tripathi, 2020).

Almost, half of Europeans, Chinese, Americans, and most of the Indians accept using some form of voice recognition, and there are conclusive signs of these platforms making it to workplaces. Brooks Brothers, WeWork, Mitsui USA, Capital One, and Vonage are already using Alexa in their business model to boost the efficiency of the business and work culture (Rong, Lin, Shi, \& Yu, 2013).

\section{Completing impressive research and innovations}

There are certain blind acnes in the progressions or goods of some system of government. Innovation happens when someone lean-tos light on those vizor acnes. 
Machine learning and AI have enabled organizations to overcome these shade spots (Hedman \& Kalling, 2003).

In medicine, it could mean analyzing a patient's danger or empowering a new analytical invention into the market. In manufacturing, it means predicting defects before happening.

\section{Instantaneous analytics}

AI for business is meting out and inferring the massive amount of data in realtime. This method allows businesses to make critical decisions and act at a quicker rate, ensuring a robust competitive position of the company (Hedman \& Kalling, 2003). The AI and ML business model will play a great role for real-time data analytics. For example, in the transportation industry, drivers could get data on traffic jams based on their location and on time fine-tune their paths (Mishra \& Tripathi, 2020c, Wirtz, 2011).

\section{Improved customer understanding and gratification}

AI-based chatbots are proficient of providing quicker comeback times and better communication eminence that will help businesses increase existing customers' trustworthiness and fascinate new ones (Johnson, Christensen, \& Kagermann, 2008).

\section{Business process robotics and automated assembly}

AI is capable of managing the automation of both service transfer and production processes (Hedman \& Kalling, 2003). For example, control and maintenance of necessary environmental conditions for packing and loading of product, managing robotic and assembly lines in factories, process payments, monitor warehouse balances, register service customer requests, and more (Wirtz, 2011).

\section{Data security improvement}

Areas where data privacy is of significant importance, like the financial sector, banking services, AI, can successfully be used in the detection of fraud and unauthorized access (Mishra \& Tripathi, 2020a; Rong et al., 2013).

\section{Business model data challenges}

Industries across the globe are estimated to outside astonishing experiments and vicissitudes in the upcoming years (Åström, 2020; Kearney, 2002). It is understood that computerization and automated robotics through focused evolution will be perpetual in those variations (Agarwal, Jain, Sinha, \& Dhir, 2020; Yoffie et al., 2016). Business model impression with process and strategy is depicted as below (Fig. 5).

In the AI-driven computerization, evolution means additional intelligence from linked data and associated devices, connected social platforms, media platforms, industry platforms and big data platforms, and advances in business model transformation through synchronization of technology (Abramowitz, 1988; Agarwal et al., 2020; Åström, 2020; Gentsch, 2019; Schulte \& Liu, 2017). Statistical data performance metrics, real-time data analytics, information, and knowledge have been mounting at a confounding pace across worldwide (Dimitras et al., 1996; Huang \& Hu, 2003; Lee, 2018). 


\section{Strategy}

Layer of planning: strongly aggregated information

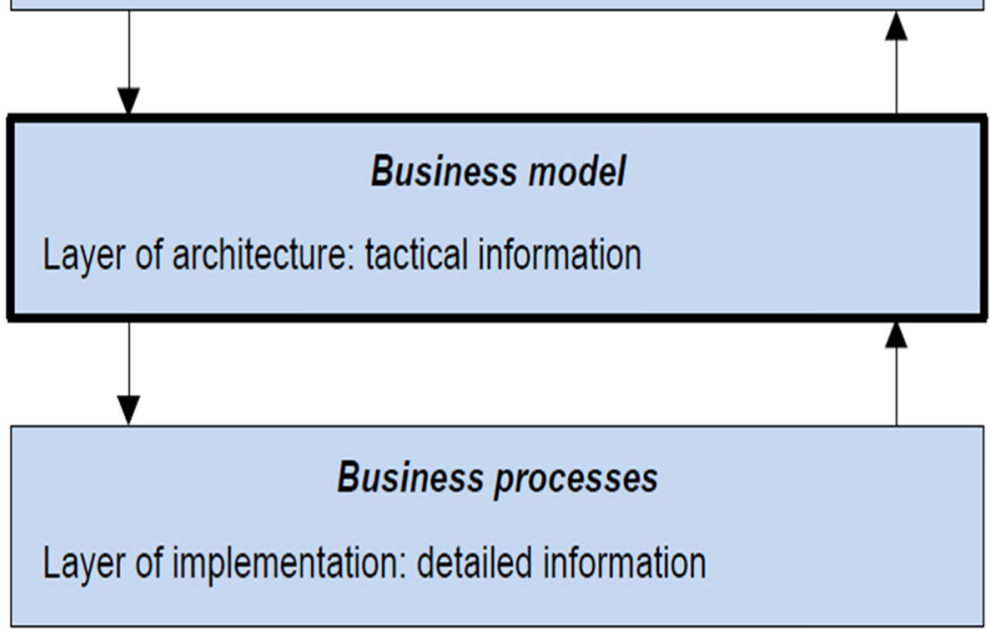

Fig. 5 Business model with process and strategy framework (Samsung White Paper, 2020)

It is indispensable to comprehend (i) how this innovative data-driven intelligence veracity takes along per capita business across the globe an exclusively new business ecosphere completes of openings and possibilities, and (ii) what are the anticipated significances and magnitudes for each current marketplace and evolving would be? The

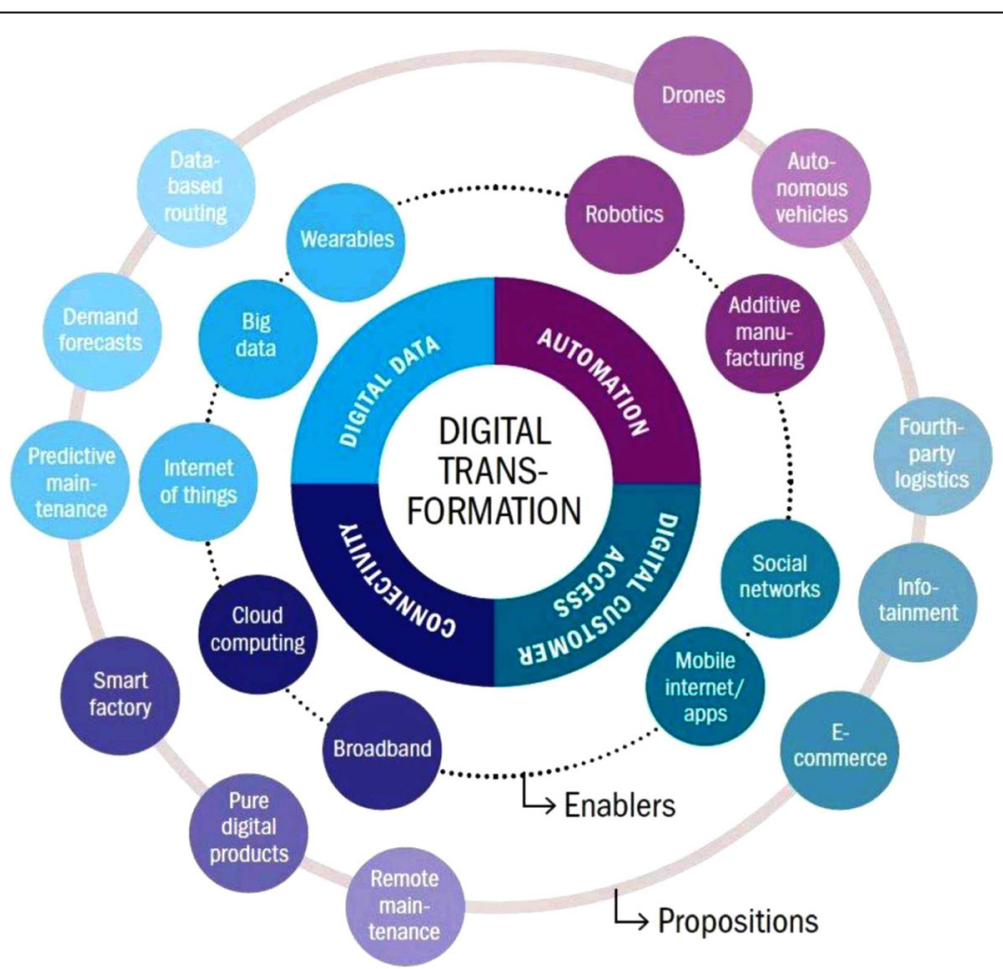

Fig. 6 Digital data transformation (Samsung White Paper, 2020) 
digital transformations boost the economy of the world at an asymptotic level (Fountaine et al., 2019; Frank, Roehrig, \& Pring, 2017; Lee, 2018). The pictorial representation of digital transformation can be shown as below (Fig. 6).

Digital businesses are establishment to cognize the consequences of the developing artificial intelligence, ambitious robotics, automatic business ecosystems, and outlying tapered artificial intelligence business dynamics (Abramowitz, 1988; Gursoy, Chi, Lu, \& Nunkoo, 2019; Liu et al., 2020; Morley et al., 2019). The data analytics and statistical computing with high-tech revolutionary artificial intelligence are convoluted (Frank et al., 2017; Gentsch, 2019; Li, Yang, Man, \& Ying, 2006). The potency, vigor and leap of artificial intelligence-driven robotic automation vicissitudes anticipated in the upcoming eons will contemporary each business encounters and breaks for its costeffectiveness. The Orchestrator model for cost-effectiveness is defined as below (Ferrario et al., 2019; Xu et al., 2018) (Fig. 7):

It will be intriguing to the spectator how the artificial intelligence changes worldwide business force and clout subtleties (Chang, Hsu, \& Lin, 2018; Gentsch, 2018a; Jarke \& Radermacher, 1988; Yoffie et al., 2016). Framework of business model is described as below (Gursoy et al., 2019) (Fig. 8):

The general AI-based business model can be depicted as below (Fig. 9):

\section{Business model transformation}

Nowadays, the whole things are getting linked with technology and devices over the internet and intranet as well (Aldinucci et al., 2018; Morley et al., 2019). Businesses now have the fortuitous to gather more digital data, get the indispensable perceptions, and revolutionize the business and thoughts (Gentsch, 2019, Huang \& Hu, 2003, Loebbecke \& Picot, 2015). As an outcome, we will most likely to see a much-needed advancement of the marketplaces: more rapidly marketplaces, thinner setups and procedures, vivacious trades and businesses, mounting returns, well-versed and up-todate customers, and vigorous and self-motivated businesses (Jarke \& Radermacher, 1988, Scheer, 2012). On the consequence, a better product provides more data and more users (Agarwal et al., 2020; Ciuriak, 2019; Corea, 2019a). This is called artificial intelligence cycle. This AI cycle can be described and elaborated pictorially as below (Åström, 2020; Kannan, Chang, \& Whinston, 2000) (Fig. 10).

These discussions generate the critical point thoughts to:

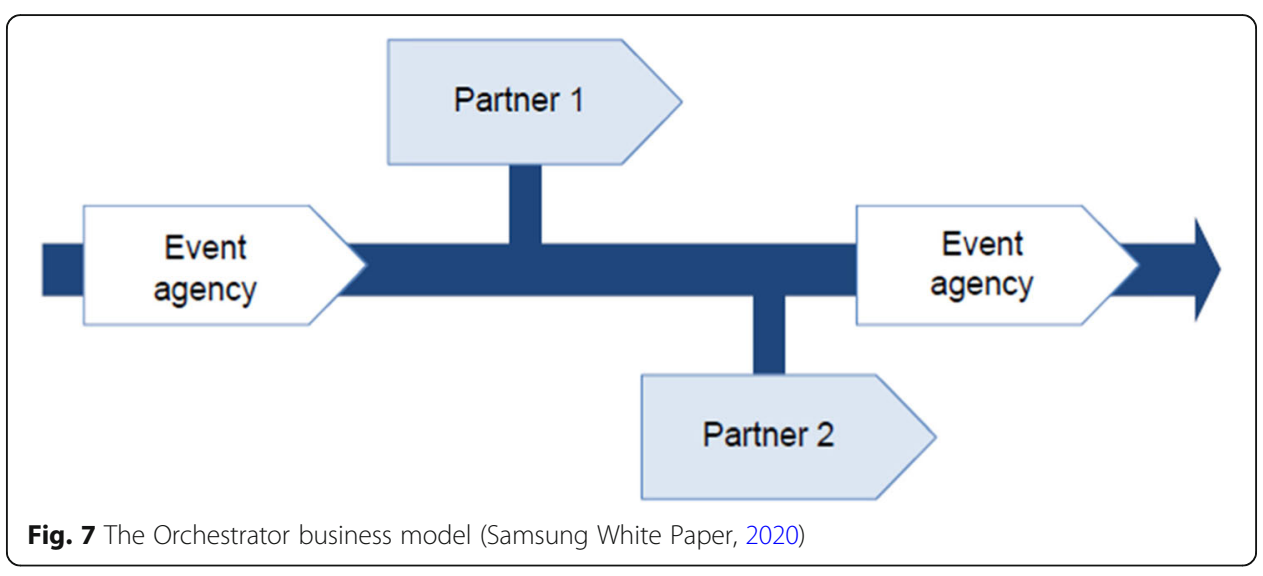



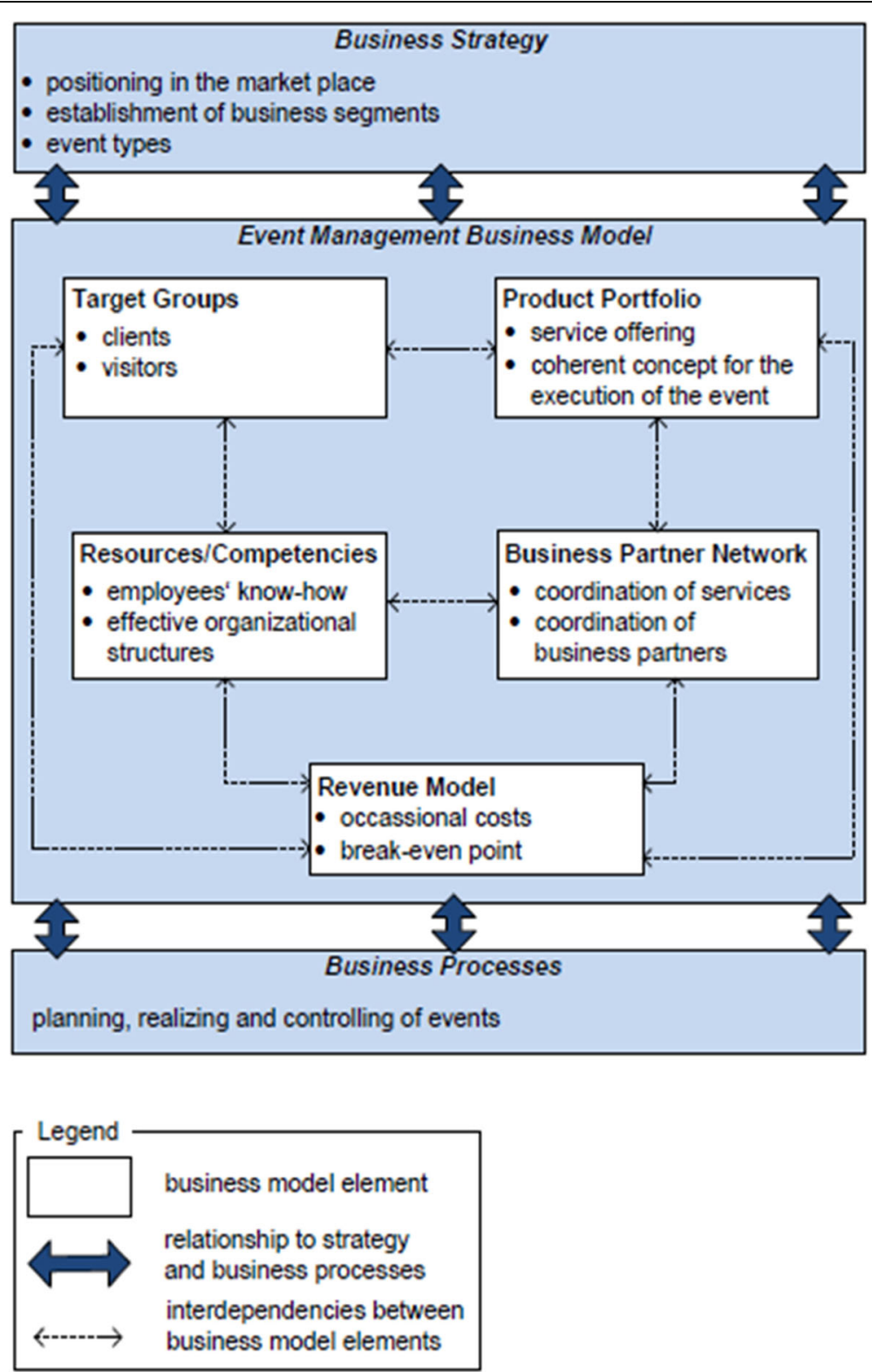

Fig. 8 Framework of Al business model (Samsung White Paper, 2020)

Research Question - How are business models being converted by AI?

While industries across the businesses and countries are at a poles apart side by side of AI acceptance, it appears that the contemporary line of attack to AI policy is excessively thin as businesses generally emphasize on using AI for enlightening customer amenities, explore and analyze data, and envisage performance to computerize amount of work, transaction, and trading and more (Fountaine et al., 2019; Kannan et al., 2000). The inclination of AI solicitation and adoption is not up to the satisfaction level and still does not return effectively to speedily developing intelligence competencies (Chui et al., 2018; Luo, Lin, \& Zheng, 2019). Also, every business so often may have a short-term business atmosphere of uncertainty and bitterness towards each other within corresponding businesses and countries 


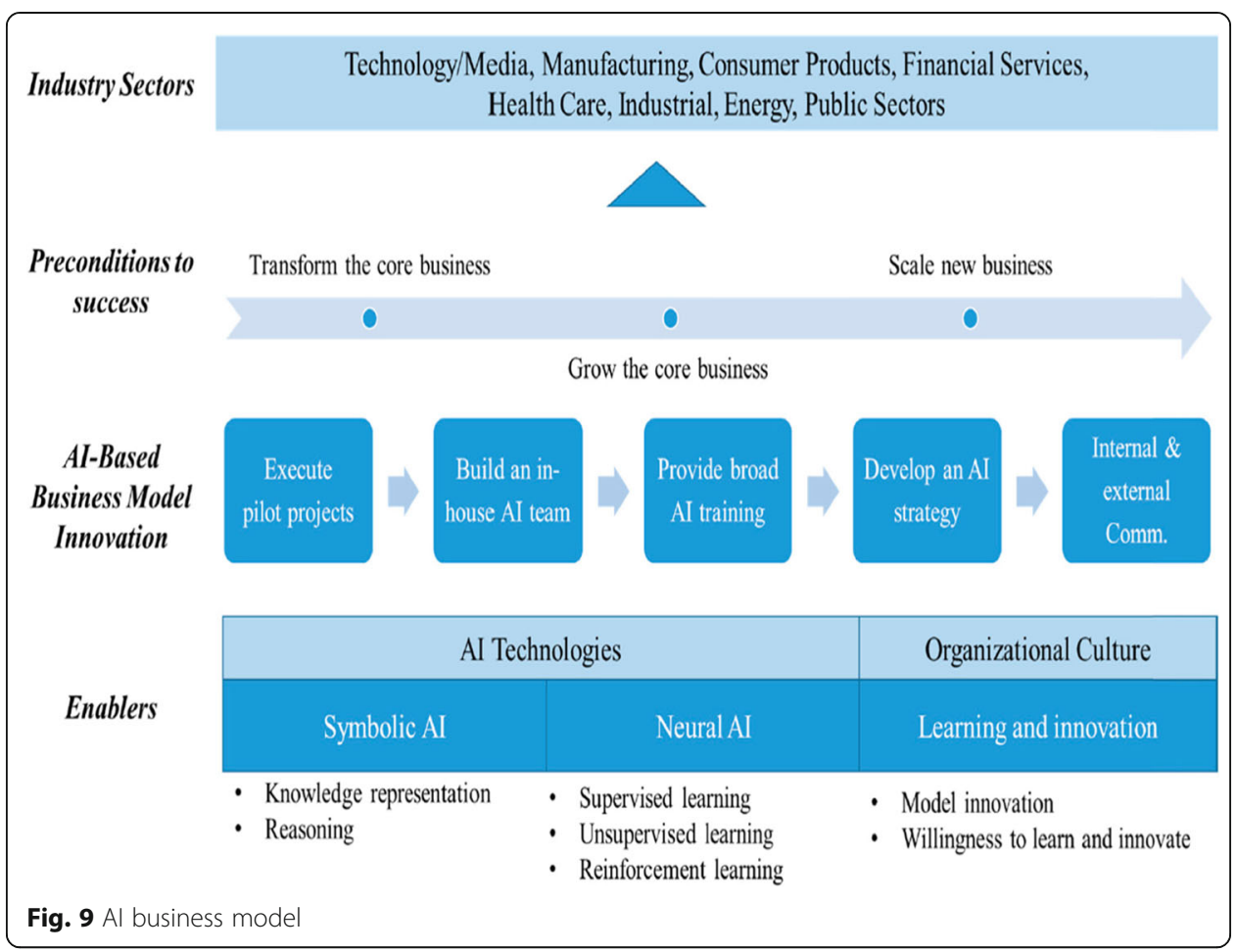

(Akerkar, 2019; Burgess, 2017). This may be one of the reasons for data collection, data analytics, and evolving information and knowledge for AI business approach. Furthermore, most of the undeveloped and underdeveloped countries is not having a potential infrastructure for digital transformation (Brock \& Von Wangenheim, 2019, Fountaine et al., 2019, Liu et al., 2020). The AI-based business is still beyond them for the establishment of essential digital data infrastructure enlargement (Chui et al., 2018; Gursoy et al., 2019). The absence of digital infrastructure, lack of opportunity, thwarts data openings and digital innovations, creating it thoughtprovoking to address business data, information and knowledge cravings sufficiently-leave-taking businesses with archaic data, information, and intelligence (Akerkar, 2019; Chui et al., 2018; Muthuveloo \& Ping, 2013). Although, the developed countries like USA, UK, European countries, and some of the Asian countries

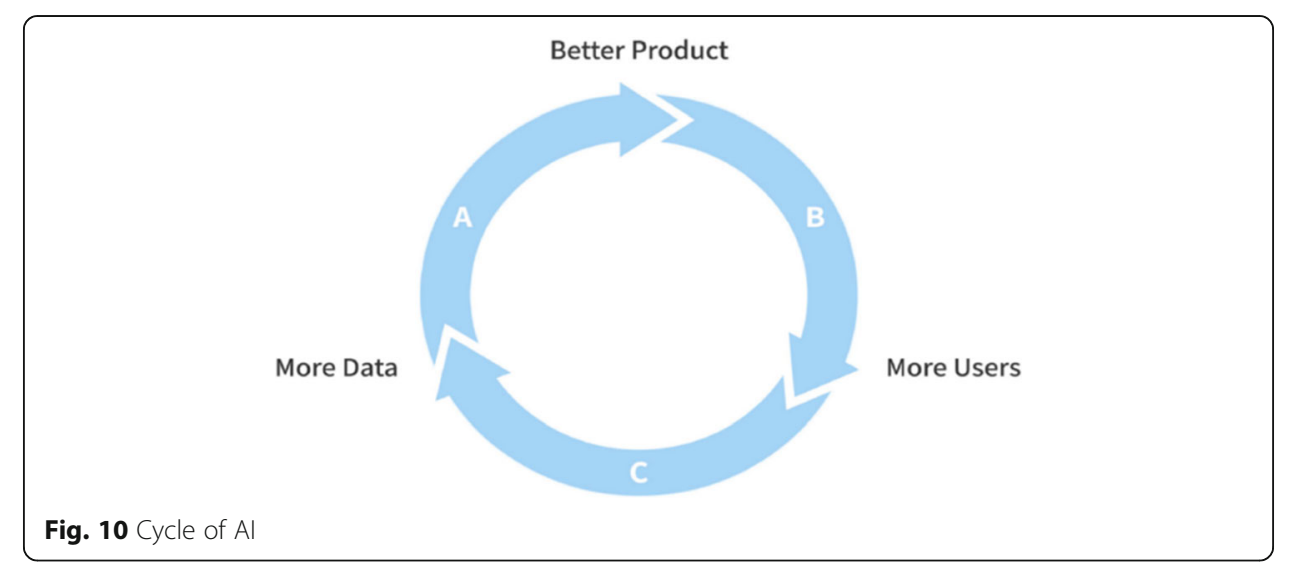


like China, Japan, Korea, India, and many more are having good infrastructure for AI-based business (Gursoy et al., 2019; Liu et al., 2020; Schank, 1991). They have competent enough software developers to apply cutting-edge decision-making technology. The Hologram technology (HT) with artificial intelligence (AI) is now new innovative trends for business and marketing (Ghoreishi \& Happonen, 2020). Samsung in their white paper (Samsung White Paper, 2020) address the concept of hologram technology and its impact on next-generation business. Samsung white papers address the issues of $5 \mathrm{G}$ vs $6 \mathrm{G}$ technology appearance and its appropriate influence on cutting edge business and explained the following Hologram technology (Samsung White Paper, 2020) (Fig. 11).

While AI and hologram have the latent to renovate businesses, state-of-the-art business models, and trade across the globe (Benkler, 2019; Corea, 2019a). Trepidations ensuing in xenophobic data practices and confrontation to partaking data, information, and knowledge may prevent its prospective. As a result, the leeway of generating and embracing huge comprehensive gigantic data ponds and live out at indigenous, countrywide, and worldwide levels go on imprecise. Hologram technology seizures truly immersive XR, high-fidelity mobile hologram, and digital replica. The pictorial outlooks are shown below as discussed in the Samsung white paper (Samsung White Paper, 2020). For a detail configuration and discussion, readings on Hologram technology researcher can refer to the white paper released by Samsung (Samsung White Paper, 2020) (Fig. 12).

Artificial intelligence is accepting the phenomenal changes of the business framework and transforming the business culture how to work in the digital era (Davenport, 2018, El-Najdawi \& Stylianou, 1993, Hamscher, 1994, Metelskaia, Ignatyeva, Denef, \& Samsonowa, 2018). Basically, it is not just changing the culture of business but also fundamentally renovating the conventional thinking and significance of alliance and collaboration, vigorous competition, and digital and enriched innovation (El-Najdawi \& Stylianou, 1993; Hagras, 2018; Niu, Li, Tang, Zhou, \& Shi, 2011; Schulte \& Liu, 2017). While most AI inventiveness craft economical improvement by recognizing an exclusively innovative opening and breaks, pleasing to the eye contemporary energies, delivering a market fragment that others business tycoons have overlooked, or crafting fresh markets, linked devices that nourish a continual creek of digital data about functionality, treatment, fabrication, requests, automated and robotic help center and more to a

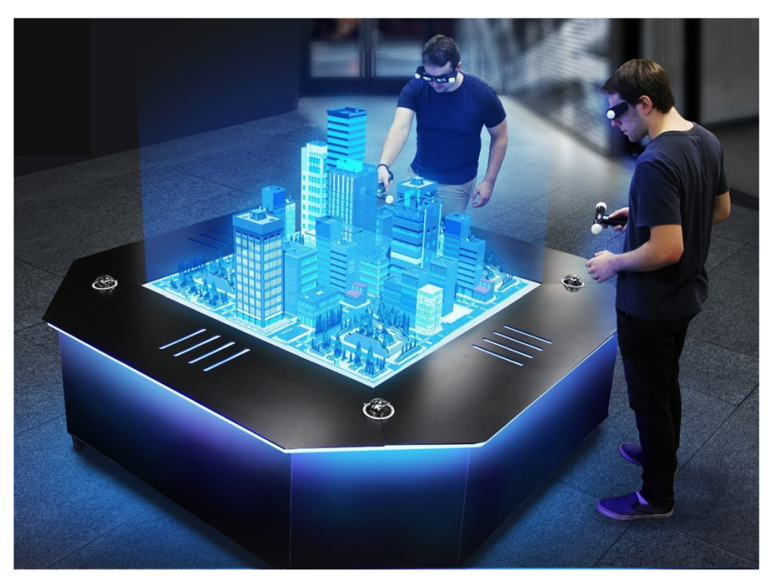

Fig. 11 Hologram technology (Samsung White Paper, 2020) 


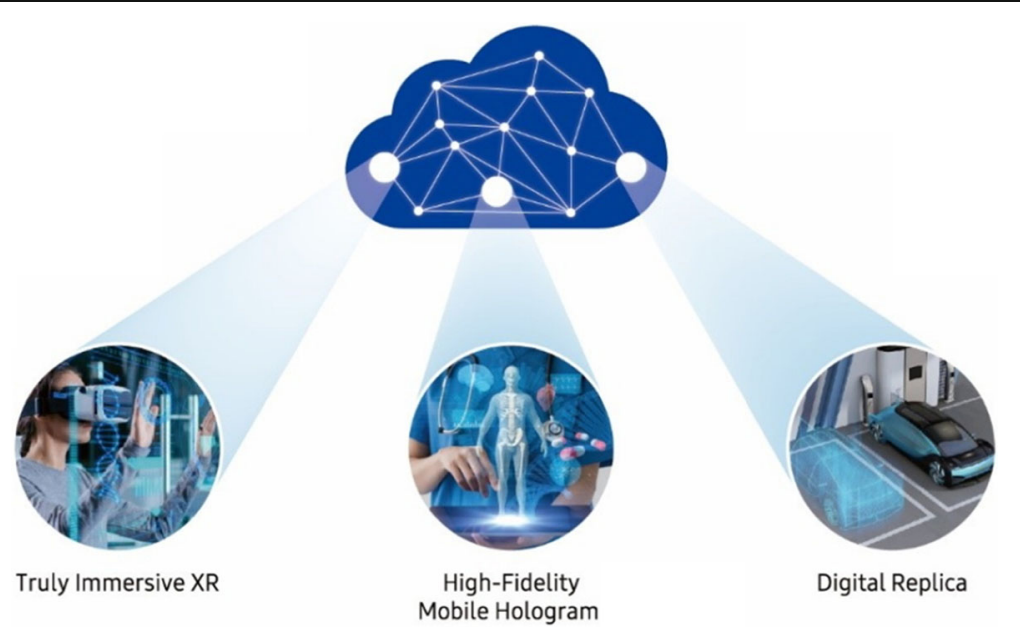

Fig. 12 Hologram technology (Samsung White Paper, 2020)

significant setting will make even more captivating economical revolutions (Gentsch, 2018, Hagras, 2018, Liu et al., 2020, Maedche et al., 2019, Scheer, 2012). This framework and technology-focused business conveys us to a key and significant point: As the Internet of Thing (IoT) amalgamation permit us for the improvement of business atmospheres where customers and trades can act and work together (Chan, 2015, Chanson, Bogner, Bilgeri, Fleisch, \& Wortmann, 2019, Schulte \& Liu, 2017, Valanarasu, 2019). How will it transform innovative business models using AI, hologram, and Internet of Things further, as it will be imaginable to enterprise strategy understandings over products and things? The technology road map of IoT is described and defined as below (Chan, 2015; Chanson et al., 2019; Schulte \& Liu, 2017; Valanarasu, 2019). This road map also depicts the growth of innovative business platform along with the respective algorithms, tools, and technology development. The security is the big issue for the state-of-the-art business model and platform (Păunescu, Pascu, \& Pop, 2016). The IoT technology roadmap is described as below (Fig. 13).

The security and privacy issues are discussed in the next section as below.

\section{Security and privacy terrorizations}

The increasing weaponization of artificial intelligence (AI) has made security a lifethreatening issue across the globe (Benkler, 2019, Clark \& Hadfield, 2019, Corea, 2019a, El-Najdawi \& Stylianou, 1993). AI is presently an extent where virtually no rules of rendezvous are put on, and each nation will surface teething troubles in making security from algorithms and defining cyber global regulation (Chanson et al., 2019; Kearney, 2002; Shae \& Tsai, 2019). In the artificial intelligence, algorithms have no boundaries and no global regulations and regulatory body, and digital data has its derivation, proprietorship, and local and global boundaries (Brock \& Von Wangenheim, 2019, Chan et al., 2019, Furman \& Seamans, 2019, Giotopoulos, Alexakos, Beligiannis, \& Stefani, 2012). There are many-including countries, situations, outworkers, offenders, and radicals - that deliberate algorithms outside the box of worldwide dominion (Shan et al., 2019). While some treaties 


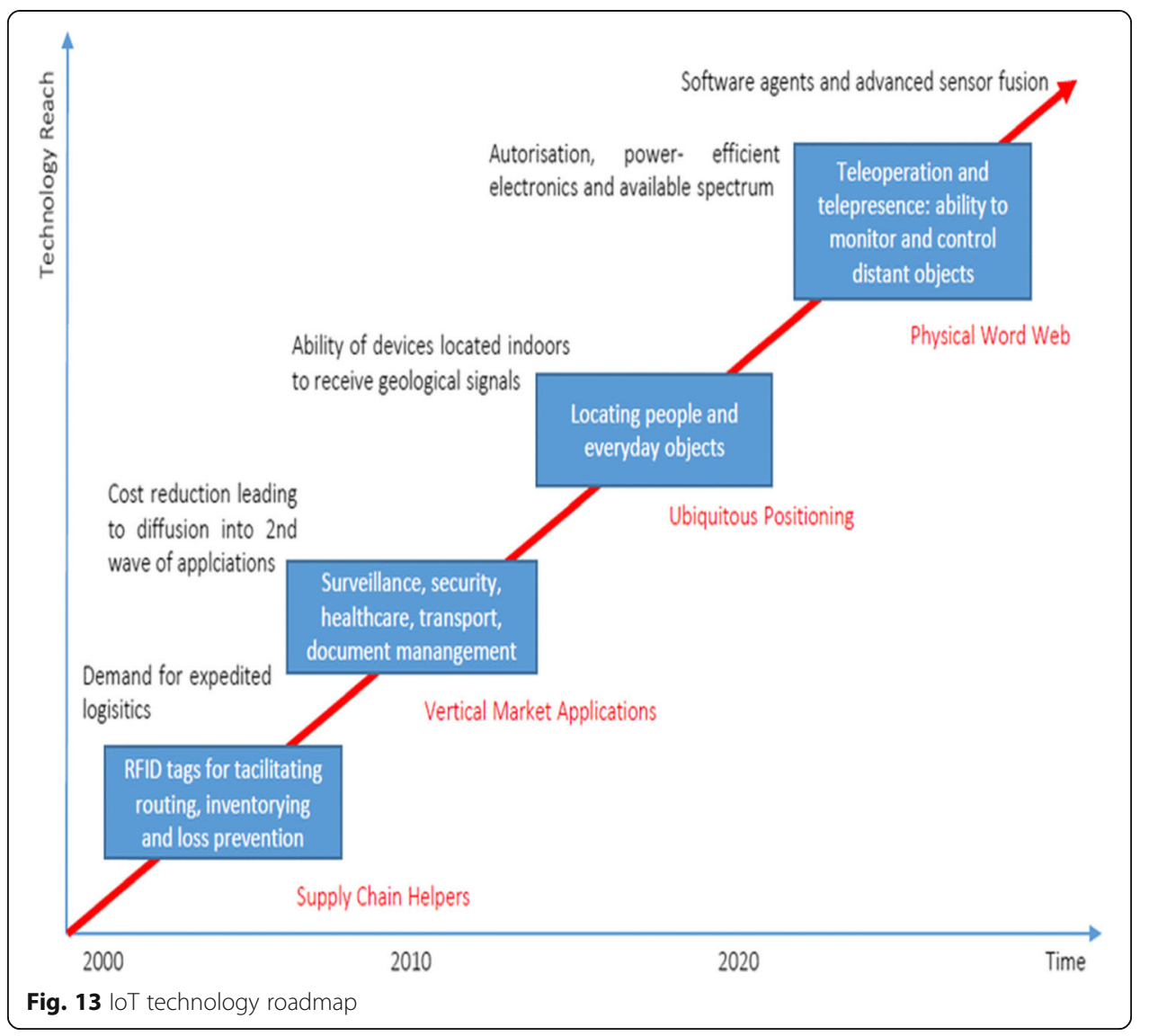

have materialized vis-à-vis cyber-crime, understanding of AI conflict leftovers open-air any obligatory legitimate commitments (Brock \& Von Wangenheim, 2019; Maedche et al., 2019). Lack of unanimity on AI guidelines, every single digital platform business model and business is at threat (Ciuriak, 2019; Dellermann et al., 2019; Hamscher, 1994; Shae \& Tsai, 2019).

Artificial intelligence (AI) is a central and fundamental chunk of the imminent which is approaching to each digital business entity across the globe (Chan et al., 2019; Clark \& Hadfield, 2019; Hagras, 2018; Shan et al., 2019). The evolving tendencies in AI-driven computerization and robotics, replicate momentous swings of companies and engagements in the artificial intelligence ecosphere that express the reconfiguration of securities, guidance, and savings in worldwide business policymaking (Ghoreishi \& Happonen, 2020; Shan et al., 2019). While quickly programming businesses present encouraging openings, they also extant noteworthy and safekeeping threats (Dellermann et al., 2019, Mishra \& Tripathi, 2020).

As the future of AI-driven digital business revolution is strictly tied to how countries accomplish their substantial data-driven competencies from across cyberspace, aqua space, and aerospace (Giotopoulos et al., 2012; Hedberg, 1996; Shan et al., 2019). There is a requirement to place a robust prominence on evolving datadriven enterprises to collect more data, information, and knowledge to evolve the AI landscape (Chang et al., 2018; Chanson et al., 2019; Iansiti \& Lakhani, 2020). 


\section{Results and discussion}

We have studied various elite and high impact factor journals in the area and elaborated the findings through critical comments and discussions. We have given the theoretical foundation of the AI in business model which capture the market in near future. We tried to give the answer how the AI and hologram technology transform the business model and change the business dynamics through numerous deliberations. The contemporary study adds to academic world and industries in two ways. First, this research and review attempted to define AI technology as the digital and algorithmic catalyst of business model innovation. More studies are called for to subordinate emergent algorithmic and technological expertise to business model innovation (Iansiti \& Lakhani, 2020; Lo'ai, Mehmood, Benkhlifa, \& Song, 2016). Second, these studies leantos graceful on reliant dynamics influencing digital business model innovation instigated by the evolving technology. Our case study and ensuing argument on the formation of digitally artificial intelligence-centered business model innovation make available understandings on such reliant features. Developments in AI technology and big data analytics will remain to generate openings and experiment to delivery systems (Daugherty \& Wilson, 2018, Kokkinaki, Dekker, De Koster, Pappis, \& Verbeke, 2002). Active front-runners require to discover new and innovative paths and ways to influence and control these improvements to makeover their business and drive evolution (Kokkinaki et al., 2002, Mishra \& Tripathi, 2020a, Wang et al., 2019a, b). Many business tycoons will find that these progresses take them in guidelines they had certainly not well-thought-out (Iansiti \& Lakhani, 2020). The focus on a business's essential proficiencies and business planning and digital strategy remains commanding but outstanding sweeping to and promising and boosting digital innovations that transference the corporation's AI-based digital business model signifies a foremost encounter for business tycoons and frontrunners (Iansiti \& Lakhani, 2020; Lo'ai et al., 2016). The innovation has become a key focus of business privileged, but enterprises free-for-all to locus themselves to perceive evolving indications of interference and to retort (Dellermann et al., 2019). This is on the whole true for businesses that have been in trade for a number of an inordinate length of time and attained extraordinary realization, i.e., inheritance digital businesses (Chang et al., 2018; Gentsch, 2018; Milkau, 2019; Wang et al., 2019a, b). The C-level chief executives know the snug to their inheritance business which emasculates their business's upcoming well-being (Wang et al., 2019a, b). It is suggested that three requirements overlay the approach to success: transmute the fundamental business, grow the central business, and scale up new business through innovation and intelligence (Milkau, 2019; Rathod \& Rathod, 2006). We believe that for numerous businesses, altering and developing the central business will yield significance over scrambling a new and innovative business since businesses must emphasize utmost of their responsiveness on the business producing the most returns (Takeuchi \& Yamamoto, 2019). If businesses and companies start a new venture, these will be expected to a derivative of endeavors to revolutionize from place to place bequest big business or possibly more expected heritage classifications. Businesses are progressively observing for workforces who can modernize and who have a ground-breaking approach because they diagnose the requirement for teams who see foremost hitches, view them as openings, and devise ground-breaking elucidations (Muthusamy, Slominski, \& Ishakian, 2018; Paul, Haque Latif, Amin Adnan, \& Rahman, 2019). 
Let us illustrate through an intangible example-suppose company $\mathrm{X}$ had some of the most cutting-edge technology in its HGVs, permitting the drivers to transport manufactured goods more proficiently and thus more cost-effectively, yet company $\mathrm{X}$ had some of the most antediluvian classifications for running and managing the society crosswise of its commercial ventures. Deprived of the persons, the HGVs park themselves shiftless. Only when the persons adjacent of the corporate activated to turn the transport on the side did they look for exterior proficiency to get-up-and-go modernization over and done with their endowment controlling practices. Similarly, only when company Y looked for to upgrade to 1000 staffs did it develop hyperfocused on the public slanted of its commercial and seek out information and proficiency it did not have. Spread over big data analytics to its public progressions created melodramatic results, but it seized an open-air perception and high-tech assets to accomplish it (Ghoreishi \& Happonen, 2020; Kokkinaki et al., 2002). It would be expected to examine why the two companies in our circumstances were incapable to revolutionize on the inside to put on the state-of-the-art developments in technology and bring up-to-date archaic and virulent coordination (Lee \& Ha, 2018, Ligęza \& Potempa, 2014). The response is that as with various businesses nowadays, these businesses do not have AI players on pointer and have not well-thought-out how to meritoriously use AI conferring to the references (Ghoreishi \& Happonen, 2020). If enterprises stand-in better erudition about Artificial Intelligence and use of AI surrounded by their set-ups, this will comfort ambition modernizations across their businesses. Furthermore, the ethos of the association expected the stage a most important starring role as the preceding segment of emerging AI-base commercial prototypical signifies (Ciuriak, 2019; Gentsch, 2018a; Mrass, Peters, \& Leimeister, 2018). The collected works and research findings suggest that executive influences performance a precarious starring role in modeling the progression of digital business model modernization (Mishra \& Tripathi, 2020, Okuda \& Shoda, 2018). The argument recurrently spins from place to place circumstantial dynamics such as managerial and executive design, legislative values and philosophy, and managerial ethics and principles (Charif \& Awad, 2014, Macmillan \& Burgess, 2017).

\section{Conclusions}

This study first delivers an ephemeral impression of AI, contemporary issues being attempted in evolving AI, and describes how it transmutes digital platform business models. Our reading of companies that revolutionized their business models using artificial intelligence shows its prospective sway. We also deliberate how managers can craft an innovative AI-based ethos, which rearticulates the progression of AI-based business model modernization. Businesses that effectively take advantage of AI can make an unsettling revolution from side to side their new digital business models and practices, empowering them to possibly transmute the worldwide economical business landscape. It seems emerging a culture of novelty often runs antagonistic to by conventional design and self-conscious interpretation. Significant fulcra entail a positive degree of freedom to take possibilities and revelation to a lens that is unaccustomed. Uppermost executives and leaders, perform a significant and strategic starring role in instituting the culture of a business so they must exemplary revolution and a readiness to frequently learn and innovate with state-of-the-art-technology. They could open by 
culture with cutting edge technology-AI and by what method it can enrich the enterprise's AI business model and coordination, as well as boosting and gratifying workforces who attain AI proficiency and take-off flyer ventures in the business.

\section{Abbreviations}

1G: First generation; 2G: Second generation; 3G: Third generation; 4G: Fourth generation; 5G: Fifth generation; 6G: Sixth generation; Al: Artificial intelligence; Bl: Business intelligence; Cl: Continuous intelligence; CRM: Customer Relationship Management; ERP: Enterprise Resource Planning; BM: Business model; DBM: Digital business model; DP: Digital platform; MI: Machine intelligence; Cl: Computation intelligence; IR: Innovation radar; PBM: Platform business models

\section{Acknowledgements}

The authors are highly thankful to the editors and reviewers for kind suggestions and critical comments for the improvement of the paper. I am also very thankful to anonymous reviewers for scrupulously reading the manuscript and providing suggestions and critical comments for improvement of the manuscript.

\section{Authors' contributions}

The first and corresponding author is responsible for literature review, analysis and critical comments. The second author is responsible for supervision. We have studied various literatures in the connecting fields. Both the authors read and approved the final manuscript. Both authors made substantial contributions, approved the submitted version, and agreed both to be personally accountable for the author's own contributions and to ensure that questions related to the accuracy or integrity of any part of the work, even ones in which the author was not personally involved, are appropriately investigated, resolved, and the resolution documented in the literature.

\section{Funding}

Not applicable.

Availability of data and materials

For reasons of anonymization, the empirical material is not available.

\section{Declaration}

\section{Competing interests}

The authors declare that they have no competing interests.

Received: 9 October 2020 Accepted: 19 March 2021

Published online: 02 July 2021

\section{References}

Abramowitz, A. I. (1988). An improved model for predicting presidential election outcomes. PS: Political Science \& Politics, 21(4), 843-847.

Agarwal, Y., Jain, M., Sinha, S., \& Dhir, S. (2020). Delivering high-tech, Al-based health care at Apollo Hospitals. Global Business and Organizational Excellence, 39(2), 20-30.

Akerkar, R. (2019). Artificial intelligence for business. Springer.

Aldinucci, M., Rabellino, S., Pironti, M., Spiga, F., Viviani, P., Drocco, M.., ... Drago, I. (2018, May). HPC4Al: an Al-on-demand federated platform endeavour. In Proceedings of the 15th ACM International Conference on Computing Frontiers, (pp. 279286).

Alhashmi, S. F., Salloum, S. A., \& Abdallah, S. (2019, October). Critical success factors for implementing artificial intelligence (Al) projects in Dubai government United Arab Emirates (UAE) health sector: Applying the extended technology acceptance model (TAM). In International Conference on Advanced Intelligent Systems and Informatics, (pp. 393-405). Springer.

Antón, A. I., McCracken, W. M., \& Potts, C. (1994, June). Goal decomposition and scenario analysis in business process reengineering. In International Conference on Advanced Information Systems Engineering, (pp. 94-104). Springer.

Armour, J., \& Sako, M. (2020). Al-enabled business models in legal services: from traditional law firms to next-generation law companies? Journal of Professions and Organization, 7(1), $27-46$.

Arnold, T., \& Scheutz, M. (2018). The "big red button" is too late: an alternative model for the ethical evaluation of Al systems. Ethics and Information Technology, 20(1), 59-69.

Åström, J. (2020). Value creation and value capture in Al offerings: A process framework on business model development.

Benkler, Y. (2019). Don't let industry write the rules for Al. Nature, 569(7754), 161-162.

Brock, J. K. U., \& Von Wangenheim, F. (2019). Demystifying Al: What digital transformation leaders can teach you about realistic artificial intelligence. California Management Review, 61(4), 110-134.

Burgess, A. (2017). The Executive Guide to Artificial Intelligence: How to identify and implement applications for Al in your organization. Springer.

Burgess, A. (2018). Al in Action. In The Executive Guide to Artificial Intelligence, (pp. 73-89). Palgrave.

Casadesus-Masanell, R., \& Ricart, J. E. (2011). How to design a winning business model. Harvard Business Review, 89(1/2), $100-$ 107.

Chan, H. C. (2015). Internet of things business models. Journal of Service Science and Management, 8(04), 552.

Chan, L., Morgan, I., Simon, H., Alshabanat, F., Ober, D., Gentry, J., ... Cao, R. (2019, June). Survey of Al in cybersecurity for information technology management. In 2019 IEEE Technology \& Engineering Management Conference (TEMSCON), (pp. 18). IEEE.

Chang, T. M., Hsu, M. F., \& Lin, S. J. (2018). Integrated news mining technique and Al-based mechanism for corporate performance forecasting. Information Sciences, 424, 273-286. 
Chanson, M., Bogner, A., Bilgeri, D., Fleisch, E., \& Wortmann, F. (2019). Blockchain for the loT: privacy-preserving protection of sensor data. Journal of the Association for Information Systems, 20(9), 10.

Charif, B., \& Awad, A. I. (2014, September). Business and government organizations' adoption of cloud computing. In International Conference on Intelligent Data Engineering and Automated Learning, (pp. 492-501). Springer.

Chui, M., Manyika, J., Miremadi, M., Henke, N., Chung, R., Nel, P., \& Malhotra, S. (2018). Notes from the Al frontier: Insights from hundreds of use cases. McKinsey Global Institute.

Ciuriak, D. (2019). Economics of Al/ML and big data in the data-driven economy: Implications for Canada's Innovation Strategy. In ML and Big Data in the Data-Driven Economy: Implications for Canada's Innovation Strategy (March 25, 2019).

Clark, J., \& Hadfield, G. K. (2019). Regulatory markets for Al safety. arXiv preprint arXiv:2001.00078.

Corea, F. (2019). Applied artificial intelligence: Where Al can be used in business, (vol. 1). Springer International Publishing.

Corea, F. (2019a). How Al is changing the insurance landscape. In Applied Artificial Intelligence: Where Al Can Be Used In Business, (pp. 5-10). Springer.

Daugherty, P. R., \& Wilson, H. J. (2018). Human+ machine: Reimagining work in the age of Al. Harvard Business Press.

Davenport, T. H. (2018). The Al advantage: How to put the artificial intelligence revolution to work. MIT Press.

Dellermann, D., Calma, A., Lipusch, N., Weber, T., Weigel, S., \& Ebel, P. (2019, January). The future of human-Al collaboration: A taxonomy of design knowledge for hybrid intelligence systems. In Proceedings of the 52nd Hawaii International Conference on System Sciences.

Dimitras, A. l., Slowinski, R., Susmaga, R., \& Zopounidis, C. (1999). Business failure prediction using rough sets. European Journal of operational research, 114(2), 263-280.

Dimitras, A. I., Zanakis, S. H., \& Zopounidis, C. (1996). A survey of business failures with an emphasis on prediction methods and industrial applications. European Journal of Operational Research, 90(3), 487-513.

Eiteman, D. K., Stonehill, A. I., \& Moffett, M. H. (1989). Multinational business finance. Pearson Education India.

El-Najdawi, M. K., \& Stylianou, A. C. (1993). Expert support systems: Integrating Al technologies. Communications of the ACM, 36(12), 55-ff.

Ferrario, A., Loi, M. \& Viganò, E (2020). In Al We Trust Incrementally: a Multi-layer Model of Trust to Analyze Human-Artificial Intelligence Interactions. Philos. Technol. 33, 523-539. https://doi.org/10.1007/s13347-019-00378-3.

Fountaine, T., McCarthy, B., \& Saleh, T. (2019). Building the Al-powered organization. Harvard Business Review, 97(4), 62-73.

Frank, M., Roehrig, P., \& Pring, B. (2017). What to do when machines do everything: How to get ahead in a world of ai, algorithms, bots, and big data. Wiley.

Furman, J., \& Seamans, R. (2019). Al and the economy. Innovation Policy and the Economy, 19(1), 161-191.

Gentsch, P. (2018). Al in marketing, sales and service: How marketers without a data science degree can use Al, big data and bots. Springer.

Gentsch, P. (2019). Al Business: Framework and maturity model. In Al in Marketing, Sales and Service, (pp. 27-78). Palgrave Macmillan.

Ghoreishi, M., \& Happonen, A. (2020). New promises Al brings into circular economy accelerated product design: A review on supporting literature. In E3S Web of Conferences, (vol. 158, p. 06002). EDP Sciences.

Giotopoulos, K., Alexakos, C., Beligiannis, G., \& Stefani, A. (2012). Bringing Al to e-learning: The case of a modular, highly adaptive system. In Advancing Education with Information Communication Technologies: Facilitating New Trends, (pp. 126138). IGl Global.

González-González, I., \& Jiménez-Zarco, A. I. (2014). The MOOC phenomenon: The current situation and an alternative business model. In elearn Center Research Paper Series, (pp. 26-33).

Gursoy, D., Chi, O. H., Lu, L., \& Nunkoo, R. (2019). Consumer's acceptance of artificially intelligence (Al) device use in service delivery. International Journal of Information Management, 49, 157-169.

Hagras, H. (2018). Toward human-understandable, explainable Al. Computer, 51(9), 28-36.

Hamscher, W. (1994). Al in business-process reengineering. Ai Magazine, 15(4), 71-71.

Hedberg, S. R. (1996). Al tools for business-process modeling. IEEE Expert, 11(4), 13-15.

Hedman, J., \& Kalling, T. (2003). The business model concept: theoretical underpinnings and empirical illustrations. European journal of information systems, 12(1), 49-59.

Huang, Z., \& Hu, Y. Q. (2003, November). Applying Al technology and rough set theory to mine association rules for supporting knowledge management. In Proceedings of the 2003 International Conference on Machine Learning and Cybernetics (IEEE Cat. No. 03EX693), (vol. 3, pp. 1820-1825). IEEE.

lansiti, M., \& Lakhani, K. R. (2020). Competing in the Age of Al.

Jarke, M., \& Radermacher, F. J. (1988). The Al potential of model management and its central role in decision support. Decision Support Systems, 4(4), 387-404.

Johnson, M. W., Christensen, C. M., \& Kagermann, H. (2008). Reinventing your business model. Harvard business review, 86(12), 57-68.

Kannan, P. K., Chang, A. M., \& Whinston, A. B. (2000). Electronic communities in e-business: Their role and issues. Information Systems Frontiers, 1(4), 415-426.

Kearney, P. (2002). Integrating Al planning techniques with workflow management system. Knowledge-Based Systems, 15(5-6), 285-291.

Kokkinaki, A. I., Dekker, R., De Koster, M. B. M., Pappis, C., \& Verbeke, W. J. M. I. (2002, April). E-business models for reverse logistics: Contributions and challenges. In Proceedings. International Conference on Information Technology: Coding and Computing, (pp. 470-476). IEEE.

Kosinski, M., Stillwell, D., \& Graepel, T. (2013). Private traits and attributes are predictable from digital records of human behavior. Proceedings of the national academy of sciences, 110(15), 5802-5805.

Lee, K., \& Ha, N. (2018, January). Al platform to accelerate API economy and ecosystem. In 2018 International Conference on Information Networking (ICOIN), (pp. 848-852). IEEE.

Lee, K. F. (2018). Al superpowers: China, Silicon Valley, and the new world order. Houghton Mifflin Harcourt.

León, M. C., Nieto-Hipólito, J. I., Garibaldi-Beltrán, J., Amaya-Parra, G., Luque-Morales, P., Magaña-Espinoza, P., \& Aguilar-Velazco, J. (2016). Designing a model of a digital ecosystem for healthcare and wellness using the business model canvas. Journal of medical systems, 40(6), 144. 
Li, C. Y., Yang, A. M., Man, J. F., \& Ying, J. (2006). An Approach to Constructing Business Model for Services Integration According to Requirement. Chinese Journal of Computers-Chinese Edition, 29(7), 1095.

Ligęza, A., \& Potempa, T. (2014). Al approach to formal analysis of bpmn models: Towards a logical model for bpmn diagrams. In Advances in Business ICT, (pp. 69-88). Springer.

Liu, F., LV, Y., Yang, P., Liu, Y., Xu, Z., \& Luo, J. (2020, April). Innovation of business model for electrical household appliance enterprises to deploy loT+ Al and loT+ 5G. In 2020 International Conference on E-Commerce and Internet Technology (ECIT), (pp. 245-247). IEEE.

Lo'ai, A. T., Mehmood, R., Benkhlifa, E., \& Song, H. (2016). Mobile cloud computing model and big data analysis for healthcare applications. IEEE Access, 4, 6171-6180.

Loebbecke, C., \& Picot, A. (2015). Reflections on societal and business model transformation arising from digitization and big data analytics: A research agenda. The Journal of Strategic Information Systems, 24(3), 149-157.

Luo, S., Lin, X., \& Zheng, Z. (2019). A novel CNN-DDPG based Al-trader: Performance and roles in business operations. Transportation Research Part E: Logistics and Transportation Review, 131, 68-79.

Macmillan, C., \& Burgess, A. (2017). The Executive Guide to Artificial Intelligence: How to identify and implement applications for $A$ in your organization. Springer.

Maedche, A., Legner, C., Benlian, A., Berger, B., Gimpel, H., Hess, T., ... Söllner, M. (2019). Al-based digital assistants. Business \& Information Systems Engineering, 61(4), 535-544.

Massa, L., Tucci, C. L., \& Afuah, A. (2017). A critical assessment of business model research. Academy of Management Annals, $11(1), 73-104$

Metelskaia, I., Ignatyeva, O., Denef, S., \& Samsonowa, T. (2018, June). A business model template for Al solutions. In Proceedings of the International Conference on Intelligent Science and Technology, (pp. 35-41).

Milkau, U. (2019). Value creation within Al-enabled data platforms. Journal of Creating Value, 5(1), 25-39.

Mishra, S. (2018). Financial management and forecasting using business intelligence and big data analytic tools. International Journal of Financial Engineering, 05(02), 1850011.

Mishra, S., \& Tripathi, A. R. (2020). Platform business model on state-of-the art business learning use case. International Journal of Financial Engineering, 07(02), 2050015. https://doi.org/10.1142/S2424786320500152.

Mishra, S., \& Tripathi, A. R. (2020a). loT Platform Business Model for Innovative Management Systems. International Journal of Financial Engineering, $2050030 \mathrm{https} / / /$ doi.org/10.1142/S2424786320500309.

Mishra, S., \& Tripathi, A. R. (2020b). Literature review on business prototypes for digital platform. Journal of Innovation and Entrepreneurship, 9, 23. https://doi.org/10.1186/s13731-020-00126-4.

Mishra, S., \& Tripathi, A. R. (2020c). Internet of everything's: Next generation business model, digital business. Elsevier (Accepted for publication).

Mishra, S., \& Triptahi, A. R. (2019). Platforms oriented business and data analytics in digital ecosystem. International Journal of Financial Engineering, 6(04), 1950036.

Morley, J., Floridi, L., Kinsey, L., \& Elhalal, A. (2019). From what to how. An overview of Al ethics tools, methods and research to translate principles into practices. arXiv preprint arXiv:1905.06876.

Mrass, V., Peters, C., \& Leimeister, J. M. (2018). Managing complex work systems via crowdworking platforms: how Deutsche Bank explores Al trends and the future of banking with Jovoto. In Proceedings of the 51st Hawaii International Conference on System Sciences (2018).

Muthusamy, V., Slominski, A., \& Ishakian, V. (2018, September). Towards enterprise-ready Al deployments minimizing the risk of consuming Al models in business applications. In 2018 First International Conference on Artificial Intelligence for Industries (A/41), (pp. 108-109). IEEE.

Muthuveloo, R., \& Ping, T. A. (2013). Achieving business sustainability via I-TOP model. American Journal of Economics and Business Administration, 5(1), 15.

Niu, W., Li, G., Tang, H., Zhou, X., \& Shi, Z. (2011). CARSA: A context-aware reasoning-based service agent model for Al planning of web service composition. Journal of Network and Computer Applications, 34(5), 1757-1770.

Okuda, T., \& Shoda, S. (2018). Al-based chatbot service for financial industry. Fujitsu Scientific and Technical Journal, 54(2), 4-8.

Paul, A., Haque Latif, A., Amin Adnan, F., \& Rahman, R. M. (2019). Focused domain contextual Al chatbot framework for resource poor languages. Journal of Information and Telecommunication, 3(2), 248-269.

Păunescu, C., Pascu, A. I., \& Pop, O. (2016). Social Enterprise: How does this Way of doing Business differ from other Forms of Enterprise? Quality-Access to Success, 17(153), 7-8.

Rathod, Y., \& Rathod, R. (2006). U.S. Patent Application No. 11/171,520.

Rong, K., Lin, Y., Shi, Y., \& Yu, J. (2013). Linking business ecosystem lifecycle with platform strategy: a triple view of technology, application and organisation. International journal of technology management, 62(1), 75-94.

Samsung White Paper (July 14, 2020):https://research.samsung.com/next-generation-communications ( Retrieve on July 16, 2020 at $10.40 \mathrm{pm}$ (ST).

Schank, R. C. (1991). Where's the Al? Al magazine, 12(4), 38-38.

Scheer, A. W. (2012). ARIS—business process modeling. Springer Science \& Business Media.

Schulte, P., \& Liu, G. (2017). FinTech Is Merging with loT and Al to Challenge Banks: How Entrenched Interests Can Prepare. The Journal of alternative investments, 20(3), 41-57.

Shae, Z., \& Tsai, J. (2019, July). Al blockchain platform for trusting news. In 2019 IEEE 39th International Conference on Distributed Computing Systems (ICDCS), (pp. 1610-1619). IEEE.

Shan, L., Sangchoolie, B., Folkesson, P., Vinter, J., Schoitsch, E., \& Loiseaux, C. (2019, September). A survey on the applicability of safety, security and privacy standards in developing dependable systems. In International Conference on Computer Safety, Reliability, and Security, (pp. 74-86). Springer.

Takeuchi, H., \& Yamamoto, S. (2019). Business Al alignment modeling based on enterprise architecture. In Intelligent Decision Technologies 2019, (pp. 155-165). Springer.

Valanarasu, M. R. (2019). Smart and secure loT and Al integration framework for hospital environment. Journal of ISMAC, 1(03), 172-179.

Wang, D., Weisz, J. D., Muller, M., Ram, P., Geyer, W., Dugan, C., \& Gray, A. (2019). Human-Al Collaboration in Data Science: Exploring Data Scientists' Perceptions of Automated Al. Proceedings of the ACM on Human-Computer Interaction, 3(CSCW), 1-24. 
Wang, X., Han, Y., Wang, C., Zhao, Q., Chen, X., \& Chen, M. (2019). In-edge Al: Intelligent zing mobile edge computing, caching and communication by federated learning. IEEE Network, 33(5), 156-165.

Wirtz, B. W. (2011). Business model management. Design-Instrumente-Erfolgsfaktoren von Geschäftsmodellen, 2(1), PP-7-17. Xu, Y., Turunen, M., Ahokangas, P., Mäntymäki, M., \& Heikkilä, J. (2018, June). Contextualized business model: The case of experiential environment and Al. In Proceedings of the the 2nd Business Model Conference, Florence, Italy, (pp. 6-7).

Yoffie, D. B., Kind, L., \& Shimol, D. B. (2016). Numenta: Inventing and (or) Commercializing Al.

Yorks, L., Rotatori, D., Sung, S., \& Justice, S. (2020). Workplace reflection in the Age of Al: Materiality, technology, and machines. Advances in Developing Human Resources, 1523422320927299.

\section{Publisher's Note}

Springer Nature remains neutral with regard to jurisdictional claims in published maps and institutional affiliations.

Submit your manuscript to a SpringerOpen ${ }^{\odot}$ journal and benefit from:

- Convenient online submission

- Rigorous peer review

- Open access: articles freely available online

- High visibility within the field

- Retaining the copyright to your article

Submit your next manuscript at $\boldsymbol{\nabla}$ springeropen.com 